\title{
Educação Física no Ensino Fundamental
}

\author{
José Demontier Guedes ${ }^{1}$; Antonia Ruth de Oliveira ${ }^{2}$; Iraneuma Cosmo de Paulo
}

\begin{abstract}
Resumo: Este trabalho contém informações sobre a situação da Educação Física no Ensino Fundamental. Tem como objetivo geral conhecer o ensino da disciplina de educação física no ensino fundamental. Em relação aos objetivos específicos, busca-se observar o método de ensino quanto à teoria e pratica da disciplina, conhecer como a escola desperta o interesse dos alunos em participar das aulas da mesma, observa a relação do professor e aluno, pesquisar a opinião dos alunos com relação às aulas de educação física, verificar o progresso dos alunos durante a disciplina. A metodologia aplicada pelas próprias autoras que realizaram um questionário onde foi apurado informações dos professores e coordenadores da escola sobre a qualidade do ensino e a aprendizagem dos alunos. "A educação física é um processo pedagógico que visa à formação de cada ser humano, onde o professor busca conhecimentos para se qualificar dentro desse meio, que é a educação". Tendo como finalidade criar novas técnicas de aprendizagem para se ter uma boa aula onde todos os alunos queiram participar.
\end{abstract}

Palavras-Chave: Educação física. Escola. Aluno.

\section{Physical Education in Elementary School}

\begin{abstract}
This paper contains information on the status of physical education in elementary school. It has the general objective to know the teaching of physical education discipline in elementary school. In relation to the specific objectives, it is sought to observe the teaching method regarding the theory and practice of the subject, to know how the school arouses students' interest in participating in the classes, observes the teacher and student relationship, students with respect to physical education classes, check the progress of students during the course. The methodology used by the authors themselves who conducted a questionnaire which was verified information from teachers and school coordinators on the quality of teaching and student learning. "Physical education is a pedagogical process that aims at the formation of each human being, where the teacher seeks knowledge to qualify within that environment, which is education." With the purpose to create new learning techniques to have a good class where all the students want to participate.
\end{abstract}

Keywords: Physical education. School. Student.

\section{Introdução}

No ensino fundamental de uma escola publica de rede estadual o processo de aprendizagem dos alunos se constitui pela valorização que os mesmo dão a disciplina de educação física e ao mediador, onde este busca melhorias de ensino e monta estratégias para obter um resultado positivo durante as aulas teóricas e praticas.

\footnotetext{
${ }^{1}$ Orientador. Mestre em Ciência da Educação. Especialista em Português e Arte-Educação. Psicólogo. Pedagogo. Responsável pelo setor de Orientação Educacional e Psicossocial (Psicólogo Escolar) do Colégio da Polícia Militar do Ceará Hervano Macedo Júnior em Juazeiro do Norte/CE. Mentor/Educador Social na prevenção ao uso de drogas e violência em escolas públicas e privadas na Região do Cariri Cearense, através do Programa Educacional de Resistência às Drogas e à Violência - PROERD. Email: Proeddemontierguedes@gmail.com;

${ }^{2}$ Discente do Curso de Educação Física do Instituto Dom José. Email: antoniaruthfm@ @otmail.com.;

${ }^{3}$ Discente do Curso de Educação Física do Instituto Dom José. Email: iraneumacosmopaulo@ gmail.com.
} 
Dessa forma, a escola contribui no desenvolvimento dos alunos com projetos onde faz com quer eles sejam estimulados a participarem mais das aulas de educação física, principalmente para os meninos que ainda acreditam que a educação física é só um esporte, onde na verdade é mais que um jogo, é a disciplina que proporciona conhecimentos para se ter uma boa saúde através das atividades práticas desenvolvidas na escola.

$\mathrm{Na}$ pesquisa foi apurado informações sobre a opinião dos alunos com relação à qualidade de ensino do professor, onde foram feitas entrevistas com os alunos do $9^{\circ}$ ano " $\mathrm{B}$ e C’. Professores de Educação física e coordenadores da escola Estado da Paraíba, relata questões sobre o método de aprendizagem aplicados na escola, e também citam projeto existente na escola e o objetivo deste.

$\mathrm{O}$ presente artigo mostra como esta o andamento da aprendizagem enfatizando os benefícios que a escola busca para o aluno e as dificuldades que a mesma enfrenta para alcançar seus objetivos, estes capazes de mudar o comportamento de seus alunos para melhor.

Como instrumento de incentivo o professor usar os jogos olímpicos para motiva os alunos e mostrar para eles a importância da educação física dentro dos esportes, possibilitando aos mesmos, uma aula diferente, onde possam praticar algumas modalidades nas aulas praticas por meio de atividades lúdicas. E nas teóricas, acontecem debates sobre determinadas modalidades que contribui para o aprendizado deles.

Aponta-se na pesquisa a relação do professor e aluno, e também a relação do professor de educação física e os demais colegas de trabalho; os materiais necessários para usar durante as aulas, e como deveria ser o espaço adequado para se trabalhar com os alunos.

Numa observação feita pelas autoras durante uma aula pratica de educação física obteve resultados positivos em relação ao domínio do conteúdo por parte do professor e compreensão dos alunos sobre o conteúdo mediado.

O mais importante neste trabalho é que por, mas que tenha dificuldades no caminho os alunos incentivados pelo professor não desistem fácil, eles tem muita força de vontade e acreditam que o professor realmente tem domínio do conteúdo e acredita em seu trabalho como também em seu aluno. 
Id on Line Revista Multidisciplinar e de Psicologia

Id on Line Multidisciplinary and Psycology Journal

\section{A busca pelo o Ensino de Qualidade: enfrentando dificulades}

Vivemos num mundo onde a criança já nasce com a tecnologia nas mãos, o que interferir no desenvolvimento intelectual do ser humano, e assim fazendo com que a criança deixe de lado a vontade de aprender, ler, escrever, pesquisar em livros e revistas entre outras ferramentas, atrasando seu aprendizado até nos mais simples ato, como amarrar o cadarço, assim a criança precisa ter limites ao uso excessivo dos dispositivos, pois caso contrário se tornarão sedentárias, para elas com os meios tecnológicos cada vez mais avançados, encontra a resposta facilmente, sem ter tanto a cobrança do professor.

Porém os meios tecnológicos são de grande importância quando são usados da forma correta sem prejudicar a vida educacional do aluno. Com isso o professor busca novos conhecimentos através desses meios. E a Educação Física traz o lazer, brincar, sentimentos como a autoestima que leva a interação entre os alunos por meios das atividades propostas durante a aula de educação física.

\footnotetext{
A educação é considerada um dos setores mais importantes para o desenvolvimento de um país e especificamente do ser humano. É através dela que são repassados os conhecimentos necessários que levam os indivíduos a melhorar a qualidade de vida e consequentemente elevar o índice de crescimento de uma nação. No entanto, apesar do reconhecimento, são notórios os problemas existentes na prestação dos serviços educacionais em todos os níveis de ensino, principalmente no fundamental, que representa a base de uma educação de qualidade. (GUEDES, BRITO \& SANTANA, 2013 p. 04.)
}

Os autores falam das dificuldades que existe no ensino, apontando como base o ensino fundamental, onde é voltado um olhar mais especial, por ser um caminho longo, que requer melhorias no aprendizado. Diante disso foi avaliado que não há recursos suficientes para conseguir um resultado positivo.

\section{Observação da aula de basquete}

Numa aula prática de basquete foi observada a qualidade de ensino do professor, que conhece o conteúdo mediado, e antes dos alunos vivenciarem a pratica do basquete, eles aprenderam por meios de atividades lúdicas os fundamentos de tal modalidade, resultando num 
Id on Line Revista Multidisciplinar e de Psicologia

Id on Line Multidisciplinary and Psycology Journal

jogo competitivo entre duas turmas do $9^{\circ}$ ano. O professor traz para seus alunos novidades visando melhoria no ensino e também na adaptação dos alunos em relação ao espaço, que na maioria das vezes na escola em que ele trabalha não existe um espaço adequado para ministrar suas aulas praticas, e assim busca outros meios que leva seus alunos para vivenciar essa pratica em outro ambiente, que ofereça melhores condições.

Uma ferramenta muito importante para o professor nas aulas de educação física, é a vivencia dos valores das olimpíadas, pois o aluno ele tende a compreender com os exemplos passados pelo professor que todos merecem respeito, devem ser amigos, para assim desenvolverem suas atividades com humildade. Alem disso nas paraolimpíadas aprendem com as modalidades que chama mais atenção como o futebol de 5, e assim percebem que todos somos capazes e iguais, independentemente da diferença entre si. E também o professor costuma trabalhar as brincadeiras populares vivenciadas pelos próprios pais, como; jogo de Bila, Mata-Mata e outros, assim os alunos conhecem como era as brincadeiras e entendem que o estudo da educação física não era tão abrangente como hoje e que não existia as ferramentas que existe atualmente, mais mesmo assim os pais se divertiam e tinham disposição pra realizar tais atividades. Diante desse fato, as atividades físicas proporciona um bom condicionamento físico e possibilita sentimentos de prazer.

Os trabalhos propostos pelo educador têm como objetivo de melhorar o clima escolar, valorizando a diversidade, proporcionando o desenvolvimento de preconceitos éticos, elevando a autoestima, tendo uma boa convivência diante da sociedade, fazendo com quer seus alunos absorva o maxímo conhecimento possível e sintam-se capazes de expressar seu aprendizado.

Para tornar sua aula diferente e mais prazerosa, o professor leva outros profissionais da mesma área para falar de determinadas modalidades e possivelmente vivenciar com os alunos levando-os para outros lugares apropriados para tal pratica como natação, vôlei, tênis e etc. Isso desperta o interesse dos alunos em querer participar das aulas de Educação Física o que vem a ser uma conquista do professor em relação ao seu trabalho e a credibilidade que ele tem em seus alunos fazendo-os se sentirem capazes de realizar as atividades propostas.

O projeto existente na escola ajuda muito na qualidade de ensino da Educação Física. Por meio deste, melhorias foram aplicadas no intuito de tornar agradáveis as aulas e possibilitar o interesse dos alunos em querer progredir e muda a visão deles em respeito a educação física que para muitos é só um esporte, mais para que isso esse projeto tenha continuidade é necessário 
Id on Line Revista Multidisciplinar e de Psicologia

Id on Line Multidisciplinary and Psycology Journal

por um fim nessas greves que atrapalha o desenvolvimento escolar não só na educação física mais em todas as outras áreas.

\section{Relação entre professor e aluno, e professor de educação física com os demais colegas.}

Todo professor procura ter uma boa relação com seu aluno, de inicio ele busca ser sincero e procura conhecer seus alunos entendendo os limites de cada um, respeitando, sendo amigo, mas mostrando que a autoridade na aula é ele e cada um dos alunos deve respeita-lo.

Ter uma boa convivência com os alunos, em vez de alimentar relações conflituosas e de tensão, é uma ótima forma de garantir um ambiente saudável, muito mais propicio ao aprendizado. (PANTELIADES 2015 p. 15)

Para que a aula possa fluir bem e que o conhecimento seja compreendido, tanto o aluno quanto professor deve saber suas posições, onde e quando deve intervir, mas com respeito. $\mathrm{O}$ que favorece a aula é a relação entre eles tonando o ambiente agradável e satisfatório.

"Uma boa relação com os demais colegas das outras disciplinas favorece sentimentos de alegria e satisfação pelo seu trabalho", assim diz o professor entrevistado na pesquisa realizada, que para ele vivencia esta situação todos os dias.

Colegas de trabalho, mais de diferentes áreas mostra que independente da sua formação existe uma pessoa amiga e com quem compartilha seus conhecimentos e vivencias, fazendo com quer resultem uma nova forma de ensino através de experiências de cada um. E isso é mais um ponto positivo para se ter um ambiente saudável.

Uma boa relação tanto com seus colegas como com seus alunos, o professor de Educação Física, ele precisa disso para enfrentar os desafios do dia a dia, principalmente em sala de aula ou onde ele aplica suas aulas práticas. Pois ele estará trabalhando com adolescente que são pessoas que na maioria das vezes precisam de boas estratégias para lhe dar com eles.

Um dos desafios do professor é convencer os alunos que nas aulas práticas são necessários o uso das roupas apropriadas para realização das mesmas. Que segundo ele por mais conhecimento que os alunos tenham sobre isso, principalmente as mulheres, resistem a essa norma. Elas sempre querem ir de jeans ou saias. Enfim, torna-se um desafio que mesmo assim não o impede de realizar sua aula. Sendo assim o professor de educação física sempre 
Id on Line Revista Multidisciplinar e de Psicologia

Id on Line Multidisciplinary and Psycology Journal

deve está com autoestima para poder ministrar suas aulas com intuito de tornar agradável para todos. E isso se resulta através de uma boa relação, com seus colegas e com seus alunos.

\section{Opinião dos alunos em relação o método de ensino aplicado pelo professor e propostos pela escola}

Se sentem satisfeitos com o método, pois a cada dia vivenciam atividades que proporciona lazer e eles têm a facilidade de compreender os conteúdos, devido à forma como seu professor trabalha, pois o mesmo busca conhecimentos para inovar e criar, com isso eles também entende que a educação Física hoje, é muito importante porque ela faz com que o aluno pratique atividade física e obtenha conhecimentos benéficos proporcionados pela mesma através das aulas.

A escola traz projetos interessantes para o desenvolvimento do aluno mais ainda há questões que deixa a desejar, como a falta de material, o espaço inadequado para praticar as atividades, horários que para eles não são suficiente para suprir a necessidade do mesmo, evoluindo sua capacidade física e mental.

\footnotetext{
A Educação, direito de todos, será promovida e incentivada com a colaboração da sociedade, visando o pleno desenvolvimento da pessoa, seu preparo para o exercício da cidadania e sua qualificação para o trabalho (BRASIL, CONSTITUIÇÃO, 1988. P. 137)
}

Para que a sociedade tenha um ensino público de qualidade, devem existe possibilidades que atendam as necessidades de todos, com objetivo de preparar as crianças ao longo dos anos que terá no ensino fundamental.

\section{Metodologia}

A pesquisa de campo foi realizada na Escola Estado da Paraíba, onde foi elaborado um questionário com as questões a seguir: As aulas de Educação Física são realizadas quantas vezes na semana? Quantos professores de educação Física trabalham na escola? Como o professor avalia o aluno durante as aulas de educação física tanto na teoria quanto na prática)? Qual a relação de professor e aluno? Nas aulas práticas os alunos se vestem de forma adequada? Existe 
Id on Line Revista Multidisciplinar e de Psicologia

Id on Line Multidisciplinary and Psycology Journal

um espaço adequado para desenvolver a aula prática? Os alunos se adaptam no espaço? Quanto aos materiais, a escola possui os materiais necessários? Como o professor faz para conquistar o interesse do aluno para que o mesmo participe da aula? Qual a relação do professor de educação física com os demais colegas de trabalho? durante a aula prática o professor aplica atividades somente da atualidade ou busca preservar a origem da educação física aplicando os jogos populares vivenciados pelos nossos pais? Os professores que ministram a aula de educação física são formados na área? O aluno costuma se manifestar quando nãoestão gostando da aula, e caso isso ocorra a iniciativa para melhorar parte somente do professor ou tem a participação da coordenação? Existe algum projeto relacionado à educação física na escola? Como os alunos reagem a esse projeto e até onde este projeto pode levar o aluno em querer progredir? As aulas práticas são realizadas somente na escola? Costumam trazer profissionais de educação física de outras instituições? O aluno tem a liberdade de avaliar o professor? Esse questionário foi realizado tanto com professores como também algumas perguntas do mesmo foram feitas para os alunos em que tinham uma faixa etária de 13 a 16 anos., e teve a colaboração dos coordenadores da escola, professor e alunos do $9^{\circ}$ ano. Os quais responderam as perguntas de forma clara e objetiva. Também teve a observação das autoras numa aula prática de basquete. E foi observada a qualidade de ensino do professor em sua aula, como também sobre as vestimentas dos alunos. E como os demais que não estavam participando, se comportavam na arquibancada.

O professor trabalha as atividades da atualidade sem deixar com quer as brincadeiras vivenciadas pelos nossos pais não fiquem somente na memória mas sim, que também os alunos possam conhecer essa pratica. O mesmo trabalha os esportes fazendo com quer os alunos entendam os fundamentos e as regras por meio de atividade lúdica e que nem tudo é só futebol.

As dificuldades encontradas para realizar as atividades se baseiam mais na qualidade do espaço que não é apropriado para realizar a aula e por isso o professor tem que montar estratégias para realização de suas aulas, e fazer com os alunos se adaptem a este espaço. Quando a escola ou professor proporciona um jogo competitivo é necessário levar os alunos para outro ambiente adequado. E os coordenadores sempre estão presentes para nas decisões do professor participando do desenvolvimento de cada aluno.

No gráfico a seguir mostra os dados referente a opinião dos alunos sobre questões que atrapalha seu aprendizado como; espaço inadequado onde os mesmos praticam a atividade 
proposta pelo professor, mas que na maioria das vezes nem todos participam pelo fato de não querer ir ao um outro ambiente que possa torna a aula mais acessível para sua aprendizagem, outro são os matérias que a escola tem uma certa sobre isso, também a carga horário da aula que para eles é pouco, e um fator mais importante é as greves que acabam interferindo no desenvolvimento do aluno, fato descrito no gráfico abaixo.

\section{Dificuldades que interferem no desenvolvimento do aluno}

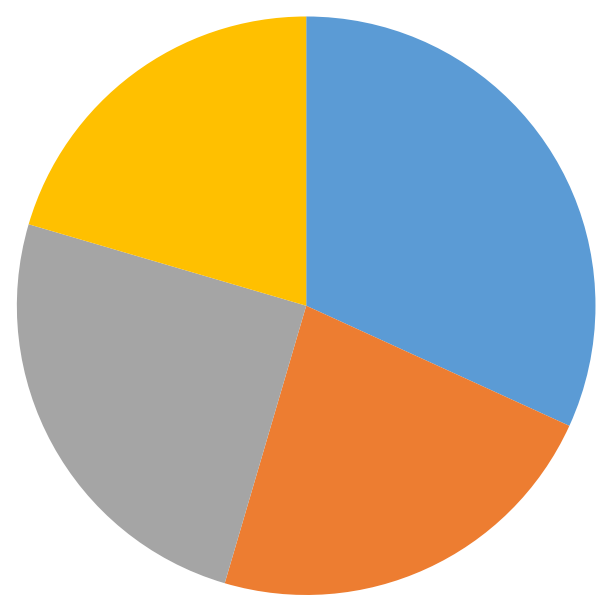

- 9o 28 Espaço Inadequado

9o 20 Os Materias

으 22 A carga Horaria

9o 18 Greves

\section{Resultados e Discussão}

A educação evoluiu bastante, mais infelizmente o que vem atrapalhando essa evolução são as greves que atingem a educação como todo, por mais que seja por motivo justo os alunos sofrem com essa questão que ainda continua sem solução.

O professor mostrou com todo o seu desempenho, que para mediar seu conhecimento não necessariamente precisa-se de materiais, mais sim a força de vontade em fazer com quer seus alunos aprendam e valorizem o que eles tem de mais precioso, o saber. Assim, levanta-se o seguinte questionamento: Como o professor faz para conquistar o interesse do aluno para que o mesmo participe da aula? 
A muitos dos alunos (vinte) entrevistados responderam, "pode faltar muitos materiais, mais que nunca falte à criatividade do professor em fazer de sua aula um precioso momento, onde aprender é o principal foco".

Só ajuda alguém a crescer aquele que propõe a crescer junto; só ensina alguma coisa aquele que está aberto para aprender e descobrir; só educa verdadeiramente quem vê diante de si uma trajetória de realização criativa, buscando sempre se renovar, demonstrando o seu profundo respeito pelo outro e pela vida (NOVAES, 2003, p. 134)

É preciso que os profissionais da educação saibam priorizar a formação continua e critica para que possam desenvolver uma educação de qualidade e que tenha um bom andamento do processo ensino-aprendizagem.

\section{Considerações Finais}

Durante a pesquisa observou-se que no ensino fundamental as aulas de educação física fazem a diferença na vida do aluno, pois nela o professor está sempre buscando mais, para transmitir ao seu aluno, novos saberes de aprendizagem e construir junto com ele algo bom que possa motivar-l o em cada etapa da sua vida.

E neste caso o professor facilita o ensino para que o aluno possa captar melhor os conteúdos estudados, proporcionando uma relação amigável e confiável perante as posições de cada um.

O projeto aplicado na escola é um dos motivos que leva o aluno a querer aprender e a participar das aulas, sabendo diferenciar esportes e atividades, mais infelizmente a carga horária não é suficiente para se trabalhar os conteúdos e o professor tem em suas mãos o desafio para que o aluno absorva-os sem se prejudicar.

A resistência em querer usar roupas normais em aulas práticas tem sido uma luta por mais que o professor diga para eles que devem-se vestir adequadamente.

Foi observado que todos os alunos gostam de educação física e raramente é encontrado alguns que não gostam. Mas infelizmente ainda existem professores que deixam a desejar, fazendo com que o aluno perca a possibilidade de conhecer de forma mais ampla tudo que se refere à educação física. E também pode se dizer que a pratica é mais preferida pelos alunos 
que a teórica, mesmo sabendo que a teórica é fundamental para se obter os conhecimentos necessários que serão utilizados na aula pratica.

Conclui-se que, o ideal do professor de educação física é transmitir para o aluno os conhecimentos da disciplina desde sua importância e sua origem, até seus conteúdos da atualidade, e adicionando as atividades vivenciadas pelos próprios pais tornando a aula dinâmica e interessante. Com isso são elaboradas estratégias pelo o educador despertando o interesse do aluno, participando das atividades.

Mostrar para os alunos que a disciplina é também uma ciência que estuda o comportamento humano, os movimentos do corpo foram também abordados na pesquisa. E isso possibilita aos alunos um estudo mais apropriado da disciplina. Por isso resulta que deve ter um horário mais específico para as aulas de Educação Física ou seja aulas mais estendidas para que os alunos possam compreender melhor essa definição sobre a disciplina. Isso é o que o professor, quer para seus alunos mais absorção dos conteúdos.

$\mathrm{O}$ ato de criar e inovar são uma das qualidades do professor de educação física, pois a todo o momento ele precisará montar estratégias para conquistar o interesse dos alunos em participar das aulas. Como por exemplo, nas aulas práticas de futebol, ele precisa convencer as meninas em participar das aulas mesmo elas não gostando. E através das atividades lúdicas ele consegue. Foi comprovado na pesquisa que isso é possível sim. Basta o professor ser criativo nas atividades, e para que isso aconteça, é necessário o educador sempre aprimorar seus conhecimentos.

\section{Referências}

MENDES, Maria Socorro dos Santos. O ideário da qualidade de ensino na escola pública: uma leitura crítica sob a ótica da Psicologia escolar. Psicol. Ensino \& Form., Brasília , v. 1, n. 2, p. 61-71, 2010 .

BRASIL. Constituição da República Federativa do Brasil, 1988.

NOVAES, M. H. Repensando a formação e o exercício profissional na escola, na sociedade pós-moderna. In: ALMEIDA, S.F.C. (Org.) Psicologia escolar: ética e competência na formação e atuação profissional. Campinas:Editora Alíena, 2003, cap.6, p.127-134 
Id on Line Revista Multidisciplinar e de Psicologia

Id on Line Multidisciplinary and Psycology Journal

\section{Como citar este artigo (Formato ABNT):}

GUEDES, J.D.; OLIVEIRA, A.R.; DE PAULO, I.C. Educação Física no Ensino Fundamental. Id on Line Revista Multidisciplinar e de Psicologia, Janeiro de 2017, vol.10, n.33, Supl 2. P.55-65. ISSN: 1981-1179.

Recebido: 04/12/2016

Aceito: $12 / 12 / 2016$ 